\title{
A noção de cultura nos estudos contemporâneos de Aprendizagem Organizacional no Brasil: desvendando a rede com o uso da inscrição literária
}

\author{
Universidade Federal do Espírito Santo / Programa de Pós-graduação em AdMinistração (PPGAdM/UFES), Vitória - ES, BraSiL \\ FAgner CARniel \\ Universidade Estadual de Maringá / Programa de Pós-graduação em CiÊnCIAs Sociais (PGC/UEM), Maringá - PR, Brasil
}

LETÍCIA Dias FANTINEL ${ }^{1}$

Universidade Federal do Espírito SANTo / Programa de Pós-graduaçÃo em AdMINISTRAÇÃo (PPGAdM/UFES), VITÓRIA - ES, BRASIL

\begin{abstract}
Resumo
O objetivo deste artigo é descrever o modo como determinadas concepções de cultura vêm sendo abordadas na disciplina de Aprendizagem Organizacional, inscrita no campo da Aprendizagem Organizacional e Gestão do Conhecimento. Para tanto, utilizou-se a noção de "inscrição literária" como princípio metodológico para a análise de redes intelectuais nas pesquisas nacionais acerca dos processos de aquisição de conhecimentos nas organizações. Exploram-se os fios que conectam os componentes dessas redes a partir da análise de um capítulo de uma coletânea de publicação recente que se propõe a realizar uma apresentação panorâmica das principais noções, perspectivas e filiações teórico-metodológicas que governam as pesquisas focadas nos processos de aprendizagem em organizações públicas e privadas pelo país. A partir da obra analisada, percebe-se a construção de uma agenda polissêmica de usos e interpretações do termo cultura. Ao final, os dados obtidos revelam como o movimento de incorporação de determinadas perspectivas sobre a cultura por parte dessa disciplina possibilitou, ao longo do tempo, certos fluxos intelectuais entre as Ciências Sociais e a Administração e impossibilitou outros.
\end{abstract}

Palavras-chave: Aprendizagem organizacional. Cultura. Campo científico. Inscrição literária. Teoria ator-rede.

The notion of culture in contemporary studies of Organizational Learning in Brazil: unfolding the network by using literary inscription

\begin{abstract}
This article aims to describe how certain conceptions of culture have been addressed in the subject Organizational Learning, within the field Organizational Learning and Knowledge Management. To do this, the notion of "literary inscription" was used as a methodological principle to analyze intellectual networks in Brazilian studies concerning the procedures to acquire knowledge in organizations. The wires that connect the components of these networks are explored through the analysis of a chapter in a recently published collection intended to provide an overview of the main notions, perspectives, and theoretical and methodological affiliations that rule research focused on learning procedures in public and private organizations across the country. By means of the work under analysis, the construction of a polysemic agenda of uses and interpretations of the term culture is noticed. In the end, data obtained reveal how the movement to incorporate certain perspectives on culture through this subject enabled, over time, certain intellectual flows between Social Sciences and Administration and prevented others. Keywords: Organizational learning. Culture. Scientific field. Literary inscription. Actor-network theory.
\end{abstract}

\section{La noción de cultura en los estudios contemporáneos sobre Aprendizaje Organizacional en Brasil: develando la red con el uso de la inscripción literaria}

\section{Resumen}

El propósito de este artículo es describir cómo ciertas concepciones de la cultura se han abordado en la disciplina del aprendizaje organizacional, inscrita en el ámbito del aprendizaje organizacional y de la gestión del conocimiento. Para ello, se utilizó la noción de "inscripción literaria" como principio metodológico para el análisis de redes intelectuales en la investigación nacional sobre los procesos de adquisición de conocimientos en las organizaciones. Se exploran los hilos que conectan los componentes de estas redes a partir del análisis de un capítulo de una colección publicada recientemente que se propone levar a cabo una presentación panorámica de las principales nociones, perspectivas y filiaciones teórico-metodológicas que rigen las investigaciones enfocadas en los procesos de aprendizaje en las organizaciones públicas y privadas de todo el país. A partir de la obra analizada, se percibe la construcción de una agenda polisémica de usos e interpretaciones del término cultura. Por último, los datos ponen de manifiesto cómo el movimiento de incorporación de determinados puntos de vista sobre la cultura por parte de esta disciplina posibilitó, con el tiempo, ciertos flujos intelectuales entre las Ciencias Sociales y la Administración e imposibilitó otros.

Palabras clave: Aprendizaje organizacional. Cultura. Campo científico. Inscripción literaria. Teoría del actor-red.

Artigo submetido em 15 de outubro de 2015 e aceito para publicação em 20 de maio de 2016

DOI: http://dx.doi.org/10.1590/1679-395157005

${ }^{1}$ A autora agradece à Fundação de Amparo à Pesquisa e Inovação do Espírito Santo - FAPES (edital FAPES 006/2014 - Universal - Projeto individual de pesquisa) e ao Conselho Nacional de Desenvolvimento Científico e Tecnológico - CNPq (processo 446524/2014-0) pelo apoio financeiro concedido. 


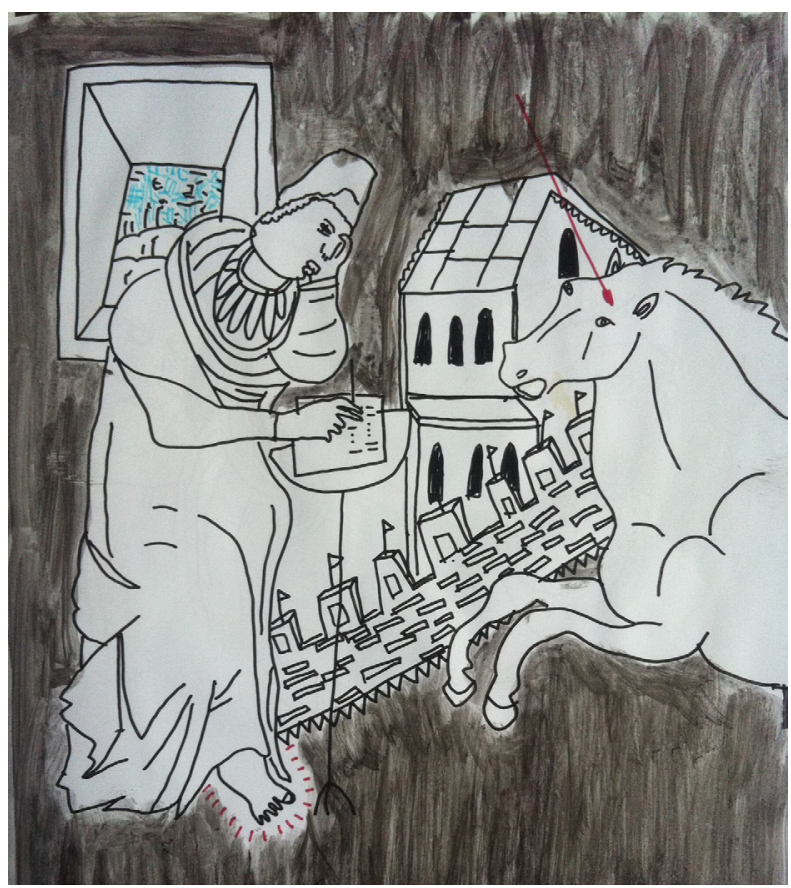

\section{INTRODUÇÃO}

No campo das Ciências Sociais, sejam elas puras ou aplicadas, é comum construtos teóricos serem desconstruídos e ressignificados continuamente. O caso do conceito de cultura é emblemático nesse sentido: palavra-mosaico, rica e ao mesmo tempo contraditória, diz respeito a valores e tradições subjacentes à condição humana, a identidades de grupos, a regras e normas existentes em determinados contextos, a padrões de pensamento e comportamento que caracterizam uma instituição (ALVES, 2010).

A noção de cultura tem diferentes acepções mesmo - ou principalmente - na Antropologia, campo de discussão do fenômeno por excelência. Diferentes escolas e correntes de pensamento apropriam-se e desenvolvem o conceito segundo seus pressupostos e suas bases epistemológicas e ontológicas, em definições que podem variar de sistema adaptativo a sistema cognitivo, bem como, ainda, sistema simbólico (LARAIA, 2009). Tal diversidade permite que diferentes concepções se aproximem mais do que outras em relações interdisciplinares. Ou seja, ao conceito de cultura cabem diferentes usos sociais e científicos (CUCHE, 2002), em acepções que são apropriadas por áreas diversas, a depender do diálogo desenvolvido entre os quadros teóricos apropriados pelo pesquisador.

As áreas da Administração e dos Estudos Organizacionais apropriam-se do conceito de forma muito variada, ilustrando o fenômeno expresso no parágrafo anterior. Os pesquisadores podem assumir posicionamentos que variam de acordo com a lente teórica e epistemológica adotada em seu estudo, bem como o próprio objeto de pesquisa (CAVEDON, 2003). Crenças, ritos, mitos, sagas, valores são analisados e interpretados de acordo com a corrente teórica escolhida pelo autor (FREITAS, 2007). Diferentes concepções podem permear tais estudos, como a compreensão da cultura como metáfora ou como variável nas organizações (SMIRCICH, 1983; PETTIGREW, 1979; CAVEDON, 2003; FREITAS, 2007), bem como o pesquisador pode ser norteado pelas abordagens de integração, diferenciação e fragmentação da cultura (MARTIN e FROST, 2001; CAVEDON, 2003).

Fonte da imagem: Disponível em http://www.escavador.com/sobre/2056573/alexandre-zampier-dos-santos-lima. Acesso em 08 jun. 2016. 
Nesse sentido, diversos domínios da Administração vêm apropriando-se de conceitos discutidos em termos da cultura, a exemplo do campo de Aprendizagem Organizacional e Gestão do Conhecimento (OLKC)². Esse campo de estudos é formado por quatro tópicos de pesquisa, que apresentam semelhanças e diferenças entre si (EASTERBY-SMITH e LYLES, 2003; 2011), a saber: Aprendizagem Organizacional (AO) (CYERT e MARCH, 1963; LAVE e WENGER, 1991; BROWN e DUGUID, 1991; COOK e YANOW, 1993), Conhecimento Organizacional (CO) (NELSON e WINTER, 1982; STARBUCK, 1992), Organização que Aprende (OA) (GARRATT, 1987; PEDLER, BOYDEL e BURGOYNE, 1989; SENGE, 1990; ALVESSON, 1993; BLACKER, 1995), e Gestão do Conhecimento (GC) (DAVENPORT e PRUSAK, 1998).

Cada um desses "subcampos" ressignifica e apropria-se diferentemente da noção de cultura. Tsang (1997), que desenvolve teoricamente uma distinção entre $\mathrm{AO}$ e $\mathrm{OA}$, o que indica que a ideia de que uma "organização aprende" dá ênfase ao processo de criação e melhora contínua da capacidade de aprendizagem das organizações. Não obstante, o conceito de cultura é central para aqueles interessados nos estudos sobre $\mathrm{AO}$, posto que essas pesquisas têm por base, visando ao desempenho organizacional, a noção de que as organizações que aprendem se desenvolvem a partir de uma cultura organizacional que propicie circunstâncias favoráveis à aprendizagem. De maneira inversa, os estudos sobre AO são processuais; descrevem e interpretam o processo social e cultural da aprendizagem nas organizações em si. O mesmo fenômeno ocorre com os tópicos de estudo CO e GC. Para Easterby-Smith e Lyles (2003; 2011), enquanto filosoficamente os primeiros buscam a natureza do conhecimento organizacional evidenciando a importância da cultura nacional e trabalhando distinções entre conhecimento tácito e explicito (e/ou individual e organizacional), aqueles que escrevem sobre GC tendem a adotar uma postura técnica na busca de desempenho organizacional por meio de conhecimentos criados e compartilhados.

Dessa forma, entende-se a OLKC como um campo (BOURDIEU, 2004; LATOUR e WOOLGAR, 1997) que apresenta variadas possibilidades no que diz respeito à abordagem do conceito de cultura. Inspirados em Latour e Woolgar (1997), a palavra "campo" é utilizada não como um lugar ou um conceito objetivo, mas como uma construção abstrata que nos permite afastar e imaginar em retrospectiva o mundo da AO, descrevendo-o pela escrita. Para esses autores, o campo é marcado pela presença de um indivíduo ambicioso, sedento por marcar pontos. Segundo Latour e Woolgar (1997, p. 239), trata-se de uma palavra complexa, pois

[...] denota simultaneamente o campo científico e a ideia de um "campo agonístico". Na segunda acepção, a palavra "campo" (usada por Bourdieu) denota o efeito de um indivíduo sobre os movimentos de todos os outros e refere-se mais a afirmações do que a uma organização.

Tal produção de fatos científicos passa pela legitimação de determinadas definições, terminologias e conceitos no campo, como a noção de cultura no campo estudado, selecionada para estudo nesta pesquisa. Considera-se relevante, nesse sentido, compreender as variadas possibilidades no que diz respeito à abordagem de tal conceito no campo de OLKC, evidenciando os caminhos pelos quais essa terminologia se constituiu como um fato na rede a ele correspondente.

Isso posto, o objetivo deste artigo é compreender o modo como determinadas concepções de cultura vêm sendo abordadas na disciplina de AO, inscrita no campo de OLKC no Brasil, a partir de um capítulo de uma coletânea brasileira sobre o assunto, considerada relevante na área. Para tanto, utilizou-se a noção de inscrição literária como princípio metodológico para a análise de redes intelectuais nas pesquisas nacionais acerca dos processos de aquisição de conhecimentos nas organizações. Exploram-se os fios que conectam os componentes dessas redes a partir da análise de um capítulo específico que compõe uma coletânea de publicação recente que se propõe a realizar uma apresentação panorâmica das principais noções, perspectivas e filiações teórico-metodológicas que governam as pesquisas focadas nos processos de aprendizagem em organizações públicas e privadas pelo país, que será indicada oportunamente neste artigo ${ }^{3}$.

Assim, este artigo apresenta a seguinte sequência: primeiro, tendo em vista a natureza deste ensaio, e considerando que o próprio referencial teórico utilizado compõe seu objeto de análise, apresentam-se os preceitos metodológicos. Logo, desvela-se

\footnotetext{
${ }^{2}$ Utilizamos Organizational Learning, Knowledge and Capabilities (OLKC) para fazer referência à principal conferência da área. Contudo, uma tradução mais adequada para Aprendizagem Organizacional e Gestão do Conhecimento seria Organizational Learning and Knowledge Management, havendo dois handbooks internacionais sobre o campo com esse título (EASTERBY-SMITH e LYLES, 2003; 2011) e outro handbook denominado Organizational Learning and Knowledge (DIERKES, ANTAL, CHILD et al., 2001).

${ }_{3}^{3}$ Parte-se da premissa de que, para compreender a construção de um fato, deve-se examinar um período particular, pois "o estudo dos períodos mais longos imporia a aceitação de um grande número de fatos, sem que fossem examinadas as suas construções" (LATOUR e WOOLGAR, 1997, p. 112).
} 
a construção social e a história da construção do campo de OLKC, bem como do diálogo entre conceitos relacionados à cultura com a disciplina de $\mathrm{AO}$, para averiguar como, atualmente, não é comum haver questionamentos sobre a possibilidade ou não da organização aprender. Depois, expõe-se uma análise das referências que o capítulo (inserido na coletânea nacional) usa e dos trabalhos que o citaram. Com base nessas operações, articula-se esse capítulo com o campo mais geral da AO, com o intento de delimitar o modo como determinadas concepções de cultura vêm sendo utilizadas e incorporadas pelos estudos de aprendizagem organizacional no Brasil. Por último, as considerações finais relatam as maneiras pelas quais este trabalho pode ser considerado um conhecimento sobre o conhecimento de cultura e aprendizagem organizacional no Brasil.

\section{APRESENTANDO O MÉTODO: A INSCRIÇÃO LITERÁRIA}

Ao indagar os sentidos e os significados que a noção de cultura vem adquirindo nos contemporâneos estudos de AO no Brasil, este artigo assume a tarefa de apresentar e problematizar algumas das maneiras particulares de produzir o conhecimento organizacional no interior dessa disciplina. Para tanto, propõe-se uma estratégia de análise que possibilite dar conta do processo de construção do conhecimento especializado. Primeiro, aproximando o leitor dos modos de enunciação dominantes na área. Depois, voltando-se sobre si para explicar os caminhos adotados e as diferentes conceituações empregadas com uma metalinguagem que não se confunda com a linguagem que se pretende investigar.

Tal deslocamento metodológico, como já observou Knorr-Cetina (1981), pressupõe que os estudos sobre as ciências podem adquirir maior profundidade e capacidade explicativa na medida em que deixam de reproduzir o que os especialistas falam ou escrevem a respeito de suas práticas para se concentrar nas micro-operações que permitiram a elaboração dos conhecimentos especializados. Nesse sentido, esta pesquisa parte do entendimento de que uma descrição das teorias de $A O$ que leve em conta apenas os termos utilizados pelos cientistas, além de permanecer incompreensível para todos aqueles que não dominam a disciplina, também encontraria dificuldades para ultrapassar a forma tautológica pela qual o discurso científico conquista sua legitimidade, por meio da reenunciação de categorias que se estabilizam mutuamente.

Desse modo, optou-se pelo uso da noção de inscrição literária, tal qual proposto por Latour e Woolgar (1997), com a expectativa de compreender como certas noções de cultura estão sendo inscritas no campo da OLKC pelos textos de AO produzidos no Brasil. Utilizada inicialmente como um recurso auxiliar na etnografia da ciência realizada por Bruno Latour junto ao Instituto Salk, na Califórnia, essa noção contribuiu para que ele e Steve Woolgar reorganizassem os traços, as atividades, os pontos, os histogramas, os registros, os espectros e os gráficos mobilizados durante o processo de produção dos fatos pertinentes à construção do conhecimento na área da neuroendocrinologia da década de 1970. Tomada de empréstimo de Derrida (1976), a noção ajudou os autores a demonstrar o caráter necessariamente incompleto, provisório e situado do conhecimento que, mesmo quando se encontra inscrito em uma forma literária específica, como ocorreu com os artigos produzidos pelo Instituto Salk, mantém aberta a possibilidade de sua ressignificação.

Sob tal perspectiva, a ideia de inscrição representa para os estudos científicos uma maneira de atentar para os momentos anteriores à publicação de um texto; ou seja, ela sintetiza um conjunto de atividades que atuam sobre as práticas científicas testando, indicando, representando, substituindo, possibilitando, confirmando ou contestando a literatura estabelecida em determinado campo. Assim, Latour e Woolgar (1997, p. 266) puderam perseguir o "processo material lento e prático pelo qual as inscrições se superpõem e as descrições são mantidas ou refutadas", reforçando o argumento de que a realidade dos fatos ou das teorias científicas seria a consequência, e não a causa, dos procedimentos incertos (artefatos) que permitiram sua postulação.

Dessa maneira, a noção de inscrição é mobilizada neste artigo como um princípio organizador da pesquisa. Por meio dela, almeja-se circular pelos caminhos do conhecimento na AO buscando os fios que atam a disciplina a certas concepções de cultura. A intenção é reorganizar a cartografia normal desse domínio disciplinar, especificamente aquela apresentada por um capítulo de uma coletânea recente na área, para transformar o que parece estar se estabelecendo como um fato inquestionável em uma nova questão de interesse. Com isso, espera-se apresentar uma visão alternativa e complementar sobre o processo de produção das teorias de AO. Trata-se, portanto, de compreendê-las enquanto resultado de escolhas intelectuais que converteram um conjunto de perspectivas em um conjunto de enunciados, que delineia o próprio desenvolvimento da disciplina. 
Portanto, a seguir descreve-se a construção social do campo de OLKC, bem como do diálogo entre conceitos relacionados à cultura organizacional com a disciplina de $\mathrm{AO}$, para averiguar como, atualmente, foram definidas determinadas noções no campo.

\section{DESCORTINANDO O CAMPO: A APRENDIZAGEM ORGANIZACIONAL A PARTIR DE SEUS HANDBOOKS}

A AO é um domínio relativamente recente dos Estudos Organizacionais, que busca dar continuidade aos estudos de aprendizagem individual e grupal nas corporações, bem como ao estudo de diferentes processos organizacionais (TAKAHASHI e FISCHER, 2009).

É possível afirmar que a AO diverge de algumas concepções consideradas por outros domínios da Administração, ao afirmar, por exemplo, que uma organização pode aprender de forma independente da aprendizagem de seus indivíduos e grupos. Em termos gerais, a constituição e a história do campo de AO se inicia com Cyert e March (1963). Segundo Easterby-Smith e Lyles (2003), essa obra pioneiramente faz referência ao termo aprendizagem organizacional, considerado parte de um modelo econômico de tomada de decisão organizacional segundo um enfoque adaptativo que dá ênfase a regras, rotinas e procedimentos como formas de reagir aos danos de um contexto exterior. Assim, pode-se entender que, implicitamente, o campo de estudos da AO é fundado a partir do conhecimento de que aspectos ditos culturais (ainda que nem sempre sejam denominados como tais) são elementos centrais do processo de mudança de comportamento organizacional para enfrentar novos e emergentes desafios. Atualmente, vale notar, a AO não é necessariamente associada a uma mudança de comportamento real e visível (ANTONELLO e GODOY, 2010).

Os trabalhos que seguiram o estudo seminal de 1963, bem como os desenvolvidos nas décadas de 1970 e 1980 , podem ser entendidos como uma série de outros estudos fundadores, na percepção de Easterby-Smith e Lyles (2003). Para esses autores, uma vez que o campo de AO foi embasado por Cyert e March (1963), outros estudos precursores trataram de entender o processo de AO. Trabalhos como o de Cangelosi e Dill (1965), por exemplo, sugeriram um modelo a partir do dualismo entre as aprendizagens individual e organizacional. Argyris e Schon (1978), seguindo uma lógica similar (opondo comportamento econômico à racionalidade econômica), colocou ênfase nos agentes humanos que detectam e corrigem erros nas teorias em uso e nos mapas mentais compartilhados, contribuindo com o campo de AO por diferenciar modelos de organizações com capacidade (ou não) de aprender. Assim, como afirmam Dierkes, Antal, Child et al. (2001), é com a ênfase atribuída por Argyris e Schon (1978) - AO como detecção de erros e indivíduo como agente - que o campo da AO inicia movimentos cíclicos para seu desenvolvimento enquanto área do conhecimento. De acordo com Shrivastava (1983), Cyert e March (1963), Cangelosi e Dill (1965) e March e Olsen (1976) integram a perspectiva de aprendizagem adaptativa e, por outro lado, Argyris e Schon (1978) e Mitroff e Emshoff (1979) integram a perspectiva compartilhamento de suposições. Segundo Shrivastava (1983), até a década de 1980 era possível discernir outras duas perspectivas de AO, a saber: desenvolvimento da base do conhecimento; e efeitos de experiência institucionalizada. Para esse autor, enquanto a primeira é desenvolvida a partir da compreensão de que a aprendizagem é um processo pelo qual o conhecimento sobre as relações de ação e resultado se desenvolvem, a segunda é desenvolvida para entender o efeito das curvas de aprendizagem na tomada de decisão gerencial.

No Brasil, no que diz respeito à década de 1960, o trabalho de Bryan (1961) pode ser entendido como uma publicação pioneira, em periódico nacional, no emprego das curvas de aprendizagem, mesmo que a partir da Teoria da Melhoria da Produção; até porque um campo de estudos de AO ainda nem havia sido inventado, para utilizar uma expressão de Roy Wagner ${ }^{4}$. Já no que concerne à participação da academia brasileira nas décadas de 1970 e 1980, uma busca no Google Acadêmico para trabalhos que façam referência à aprendizagem organizacional nesse período, sem incluir patentes ou citações, disponibiliza 13 resultados. Considerando-se que nem todos os resultados correspondem de fato à pesquisa feita, descreve-se a continuação os estudos que apresentam informações associadas à referida expressão. Tratando cronologicamente dos trabalhos nacionais

\footnotetext{
${ }^{4}$ Uma busca no Google Acadêmico para o termo 'aprendizagem organizacional' no campo brasileiro até a década de 1960 indica apenas o artigo de Bryan (1961). Para esse autor, a Teoria da Melhoria da Produção - em oposição à teoria dos psicólogos industriais - oferece curvas de melhoria de produção que permitiriam estimar o progresso futuro de uma recém-inaugurada linha de produção. Segundo Bryan (1961, p. 42), essa teoria é central para "estimar custos e necessidades futuras de mão de obra para produtos em que a aprendizagem organizacional tenha influência importante".
} 
levantados para esse período, o primeiro estudo - de Caravantes e Pereira (1981, p. 39) - contrapôs a aprendizagem organizacional (ARGYRIS e SCHON, 1974) à estratégia de mudança organizacional planejada, tendo em vista que a segunda se refere a esquemas de socialização e de adaptação dos indivíduos às organizações. A segunda pesquisa é a de Araújo (1981, p. 7), que analisa o esforço de reorganização de um órgão do Ministério de Educação e Cultura para entender a "aplicabilidade dos modelos de racionalidade subjacente ao processo de reforma administrativa" e, por outro lado, as "limitações dos modelos adotados nos processos de aprendizagem organizacional". A terceira investigação foi realizada por Fachin e Silva (1984). Em "O comportamento político do dirigente de empresa estatal na formulação de estratégias", desenvolvido em uma empresa estatal de processamento de dados (Copede), esses autores empregam o conceito de aprendizagem organizacional de Argyris e Schon (1978) para visualizar e analisar a aprendizagem organizacional e a mudança da Copede. A quarta pesquisa, de Moura (1986), propõe-se a descrição dos fenômenos de aprendizagem organizacional para diferenciá-los dos mecanismos psicológicos atuantes no fenômeno de socialização organizacional. Um último estudo foi desenvolvido por Fleury (1987) para explo$\operatorname{rar}$ A gestão de tecnologia na empresa industrial brasileira a partir da perspectiva da gestão da aprendizagem tecnológica, em oposição à abordagem da gestão da inovação. Contudo, é relevante destacar que este último estudo não se relaciona diretamente à $\mathrm{AO}$, mas participa da construção de uma lógica na Administração que passa a colocar a questão do desenvolvimento tecnológico, da gestão da inovação, como dependentes da capacidade de uma instituição organizar processos de aprendizagem. Nas décadas de 1970 e 1980, com exceção do trabalho de Caravantes e Pereira (1981), que opõem aprendizagem a mudança organizacional, os demais trabalhos demonstram que, na época, a AO era associada a uma mudança de comportamento real e visível (ANTONELLO e GODOY, 2010).

Na década de 1990, observa-se a continuidade do processo de apropriação e transformação do legado polissêmico e multidisciplinar da AO a partir de estudos anteriormente produzidos. Nesse período, a cada investigação produzida, novas conceitualizações permitiam o aumento notável de suas publicações. Foi na década de 1990 que a AO conheceu seu primeiro pico significativo de citações (PRANGE, 2001), aproximadamente 30 anos depois do trabalho inaugural de Cyert e March (1963). Na concepção de Latour e Woolgar (1997), picos como esse costumam confirmar a representação própria dos estudiosos de uma área sobre determinados postulados, suas fundações míticas e as batalhas que possibilitam sua enunciação.

É nesse momento que os estudos sobre processos de aprendizagem em organizações passam a não se preocupar tanto em reproduzir as narrativas sobre a origem do campo, pelo simples fato de que compreender que organizações aprendem passa a ser considerado verdade, por assim dizer, entre os pesquisadores da área. Dessa maneira, ao longo e depois da década de 1990, diferentes perspectivas começam a se institucionalizar como tópicos especializados e relativamente autônomos de pesquisa sobre aprendizagem e conhecimento nas organizações, constituindo os quatro tópicos de pesquisa - aludidos na introdução: AO, OA, CO e GC - do que hoje se conhece como o campo de OLKC.

Esse processo de expansão e consolidação do heterogêneo campo de Estudos Organizacionais de conhecimento e aprendizagem da década de 1990 ocorreu de forma similar no Brasil. É verdade que esse movimento começou a ganhar força apenas em 1995, quando em apenas um ano é possível identificar 14 resultados para a busca aprendizagem organizacional no Google Acadêmico. Destaca-se o trabalho de Fleury (1995). Essa pesquisa, que foi desdobrada por outros 60 trabalhos, advoga a favor de um processo contínuo de mudança organizacional por meio de processos de aprendizagem permanente. Para o ano de 1996, o Google Acadêmico indica outros 14 resultados, sendo relevante destacar os trabalhos de Fischer, Heber, Teixeira et al. (1996) e de Figueiredo (1996). Para 1997, o Google Acadêmico oferece aproximadamente 32 resultados para nossa busca, dentre os quais se destaca o trabalho de autores já mencionados, como Fleury e Fleury (1997), e de novos(as) autores(as), como Brito e Brito (1997) e Botelho (1997). Para o ano de 1998, o Google Acadêmico indica outros 49 resultados para aprendizagem organizacional e, ainda, sobressaem as pesquisas do tópico de estudos de organizações que aprendem, com destaque para a perspectiva desenvolvida a partir da relatividade cultural de Fleury e Fleury (1998). O ano de 1999, como consta no Google Acadêmico, apresenta aproximadamente 70 resultados, 35\% do total de 198 resultados para a década de 1990. Loiola e Bastos (2003) desenvolveram um estudo da produção acadêmica sobre AO no Brasil de 1997 a 2001, a partir do qual é possível observar que, nesse período, mais de 16 universidades de 10 diferentes estados brasileiros participaram da construção desse campo, sendo que, nos trabalhos desenvolvidos a partir dessas universidades, houve maior frequência dos subtemas mudança organizacional, inovação e cultura organizacional relacionados à AO.

Tal processo de construção social dessa emergente especialidade na Administração, que, ao longo da década de 1990, fez dos estudos de AO uma área de pesquisas considerada legítima, pode ser acompanhado pela apreciação de dois handbooks de 
impacto para o processo de materialização desse campo: o handbook de Estudos Organizacionais (CLEGG, HARDY e NORD, 1996; CLEGG, HARDY, LAWRENCE et al., 2006) e o handbook de OLKC (DIERKES, ANTAL, CHILD et al., 2001; EASTERBY-SMITH e LYLES, 2003; 2011).

Na visão de Clegg, Hardy, Lawrence et al. (2006), no domínio acadêmico, um handbook costuma ser uma tentativa de produzir um texto científico sobre outros textos científicos. Trata-se de um material de ensino que estrutura uma visão geral e panorâmica de determinada disciplina ou de determinados conceitos, ainda que possam ser criticados por tentar cristalizar determinados conhecimentos. Um handbook é um livro que integra diversas publicações às quais acadêmicos e práticos se referem como um fato e, ao mesmo tempo, como um artefato legítimo, controverso e disponível à palma da mão, como a própria tradução da palavra nos informa.

No que diz respeito ao conteúdo específico da segunda edição do handbook de Estudos Organizacionais (CLEGG, HARDY, LAWRENCE et al., 2006), muitos capítulos que integram essa obra, e que haviam sido previamente publicados em Clegg, Hardy e Nord (1996), foram estruturalmente revisados. Outros são inteiramente novos, devido a oportunidades brindadas por áreas emergentes. Há também o caso de diferentes capítulos presentes em Clegg, Hardy e Nord (1996) e que não constam em Clegg, Hardy, Lawrence et al. (2006). Um dos capítulos presentes em 1996 que não se encontra na segunda versão de 2006 é exatamente o que se refere ao campo de OLKC: "Aprendizagem organizacional: afirmando um oxímoro", de Weick e Westley (1996).

O primeiro handbook de OLKC foi lançado por Dierkes, Antal, Child et al. (2001). Essa obra, bem como os dois handbooks posteriormente editados por Easterby-Smith e Lyles (2003; 2011), apontam diversas perspectivas consideradas legítimas para estudar aprendizagem nas organizações: a psicológica, a aprendizagem social, a relacional, a econômica, a antropológica. Essas perspectivas se relacionam com os quatro tópicos de pesquisa desses handbooks, e que foram anteriormente mencionados: $\mathrm{AO}, \mathrm{OA}, \mathrm{GC}, \mathrm{CO}$.

Para o handbook de 2003, a força que popularizou o estudo dos processos de aprendizagem e conhecimento nas organizações foi a edição especial de Organization Science, de 1991. Isso ocorreu por dois motivos. Primeiro, para Easterby-Smith e Lyles (2003), essa edição especial conseguiu reunir uma série de artigos que mais tarde seriam responsáveis pelo já mencionado pico das citações, e permitiu a vinculação de um artigo que futuramente seria relacionado à principal vertente alternativa à tradição utilitarista dos estudos de AO. Essa visão, considerada alternativa à tradição neorracionalista - que visava à utilização eficiente do conhecimento em organizações diante de obstáculos (em sua maioria humanos) diversos (HUBER, 1991; EPPLE, ARGOTE e DEVADAS, 1991; SIMON, 1991) -, estava implícita no artigo de Brown e Duguid (1991), que afirmava, a partir de uma perspectiva situada, que deve prevalecer o processo social da AO.

Com base no exposto até o momento, foi praticável descrever com maior precisão o momento a partir do qual a noção de cultura foi trazida com centralidade para os estudos de AO, bem como as estratégias e associações que levaram a essa integração. Apesar do diálogo entre cultura e aprendizagem organizacional haver principiado já na inauguração do campo, em 1963, a partir de 1991 o conceito de cultura (sob diferentes perspectivas) passou a ser compreendido como indissociável da interpretação de processos de $\mathrm{AO}^{5}$. A partir da compreensão da construção social e histórica do campo de OLKC, julgou-se interessante descrever o modo como determinadas concepções de cultura vêm sendo abordadas na disciplina de AO no Brasil. Entretanto, uma questão pertinente colocou-se a partir dessa reflexão: como seria possível acessar a rede de pesquisadores que configura o campo?

Por meio do método da inscrição literária, seria factível partir de qualquer um dos artigos nacionais analisados até o momento para inquirir a respeito dos modos de existência da(s) cultura(s) na disciplina de AO na atualidade. Entendemos que qualquer ponto de partida para aplicar o método da inscrição literária, visando a descrever o modo como determinadas concepções de cultura vêm sendo abordadas na disciplina de AO no Brasil, seria parcial. Contudo, ao mesmo tempo, compreendemos que "uma perspectiva exterior é tão prontamente criada quanto as nossas mais confiáveis perspectivas 'interiores'" (WAGNER, 2010, p. 19). Como foi apenas na década de 2000 que o campo nacional de estudos da AO começou a refletir sobre sua própria produção, permitindo que outros trabalhos se apropriassem do legado polissêmico e multidisciplinar da AO para produzir, a

${ }^{5}$ Brown e Duguid (1991) e Lave e Wenger (1991) inauguram uma série de estudos sobre aprendizagem situada e comunidades de prática, sugerindo que as atividades e os problemas são equacionados no próprio local de trabalho por meio de interação pessoal e podendo dar lugar ao estabelecimento de subculturas dentro da organização. 
cada investigação, novas conceitualizações (contribuindo com a construção da rede brasileira de OLKC), nossa opção foi partir de um trabalho que tivesse como objetivo refletir sobre a constituição do campo da AO.

Para a década de 2000, o Google Acadêmico apresenta aproximadamente 4.660 resultados para a busca por aprendizagem organizacional, sem incluir patentes ou citações. Nesse período, são inúmeros os estudos dedicados a refletir sobre o próprio campo nacional da AO, como, por exemplo, Easterby-Smith e Araujo (2001), Antonello (2002; 2005), Loiola e Bastos (2003), Ruas e Antonello (2003), Bastos, Gondim e Loiola (2004), Ruas, Antonello e Boff (2005), Versiani e Fischer (2008), Takahashi e Fischer (2009), Antonello e Godoy (2010; 2011), Doyle e Versiani (2013). Entretanto, nenhum texto estruturado em relação à constituição de um campo nacional de $\mathrm{AO}$ parecia ser tão pertinente quanto aquele com capa preta e um título ambicioso: Aprendizagem organizacional no Brasil, contando com a colaboração de vários(as) outros(as) especialistas no tema ${ }^{6}$. A obra estava em sua primeira edição e oferecia 25 capítulos com análises de práticas, processos, concepções e estratégias metodológicas voltadas ao estudo de empreendimentos públicos e privados no país. Não tínhamos segurança sobre o que encontraríamos naquelas páginas - mesmo assim, fizemos uma aposta. Essa coletânea, organizada por Antonello e Godoy (2011), é apresentada subsequentemente.

\section{APRESENTANDO A COLETÂNEA NACIONAL: APRENDIZAGEM ORGANIZACIONAL NO BRASIL}

Recentemente, houve a publicação de uma coletânea nacional, intitulada Aprendizagem organizacional no Brasil (ANTONELLO e GODOY, 2011). Na apresentação dessa obra, redigida por Luis Araújo, esse artefato reivindica inclusão, mas sem abrir mão de suas particularidades locais. Para Luis Araújo, essa publicação representaria um significado duplamente importante: a crescente representatividade geopolítica do Brasil e a importância de estudar novas formas de organização da AO por sua extensão a outros contextos. A introdução à obra, escrita por Miguel Pina e Cunha, sob o título "The times they are a-changing: a sociedade organizacional à entrada do século XXI", assinala que esse campo em construção tem a tarefa de "descobrir como colocar e manter sistemas complexos neste espaço de criatividade e adaptação, onde a aprendizagem é mais espontânea e mais distribuída pela organização como um todo" (CUNHA, 2011, p. XXIII).

A relevância dessa coletânea passa pelas posições de destaque assumidas pelas autoras no campo, pela centralidade das universidades nas quais essas autoras construíram suas carreiras (GUIMARÃES, GOMES, ODELIUS et al., 2009), além dos próprios autores dos capítulos da obra, bem como do caráter diverso dos assuntos tratados em cada uma das seções, mas não está limitada a esses aspectos. A importância da obra não diz respeito, assim, somente a uma característica exterior ou intrínseca à coletânea, mas também a diferentes elementos relacionais - humanos e não humanos - disponíveis aos distintos interessados em compreender processos de AO no Brasil.

Essa coletânea nacional - na qual se encontra o capítulo (analisado posteriormente) que trata de cultura, práticas e aprendizagem - é composta por duas partes. A Parte I, na qual se encontra o capítulo referenciado, agrupa oito artigos que investigam possibilidades e impossibilidades discutidas a partir da teoria. Já a Parte II esquadrinha possibilidades e impossibilidades a partir de dezessete estudos empíricos. Uma vez que existia uma relação recursiva que costurava a obra pelo objetivo comum de seus autores de consolidar o campo de estudos de AO no Brasil, encarou-se como fictícia a separação da obra entre teoria e prática. Todos os capítulos teóricos e práticos são iniciados pela exposição clara de seus objetivos e apresentam resumidamente o caminho percorrido para alcançar a tarefa exposta. Outrossim, o caminho apresentado por cada artigo é marcado por inúmeros pontos de passagem que promovem o encontro de teorias (Parte I) com práticas (Parte II) de pesquisa, ou melhor, entre sujeitos (cientistas, autores, inscritores, práticos, teóricos) e objetos do conhecimento (práticas, teorias, perspectivas, métodos). Por conseguinte, a obra não apenas introduz diferentes abordagens sobre uma agenda comum de problemas de pesquisa, mas, ainda, coloca-se nesse processo, de modo a participar da produção intelectual no campo.

\footnotetext{
${ }^{6}$ Aprendizagem organizacional no Brasil, de 2011, se propõe a abrigar diferentes temáticas dentro do campo, oferecendo um painel dos principais escopos de interesse da rede. Essa coletânea se coloca em posição de mapear ao menos parte da rede e os próprios conceitos e definições por ela tratados. Nesse sentido, na medida em que mapeia a rede, evidencia diferentes conceitos e estabelece definições e terminologias para o campo, a coletânea, sendo reconhecida e legitimada como tal (o que pode ser auferido pela quantidade de citações que seus textos recebem), torna-se um instrumento relevante para o conhecimento e posicionamento dos pesquisadores na estrutura que forma o campo.
} 
Contando com um total de 25 capítulos, todos redigidos por autores e autoras a partir de distintas posições acadêmicas e/ ou profissionais, a coletânea conforma uma rede de relações institucionais (Figura 1). De modo geral, essa obra sistematiza a produção recente da AO brasileira, bem como oferece um quadro panorâmico das principais perspectivas teórico-metodológicas utilizadas por tais pesquisas.

Figura 1

Rede de relações institucionais dos(as) autores(as)

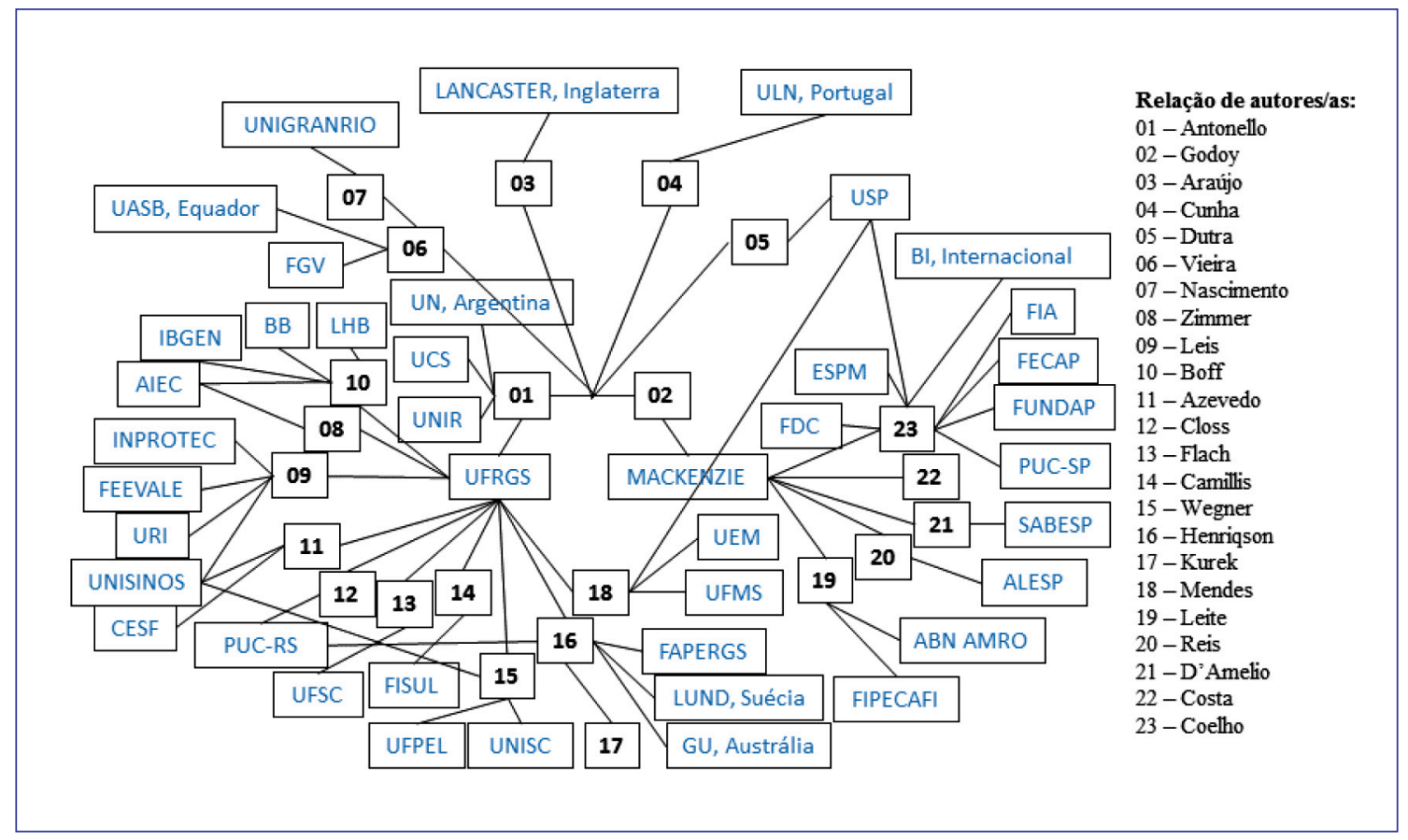

Fonte: Elaborada pelos autores.

Um desses capítulos, intitulado "Aprendizagem organizacional: explorando o terreno das teorias culturais e das teorias baseadas em práticas", de Antonello e Azevedo (2011), é dedicado ao modo como a noção de cultura, e dos Estudos Baseados em Práticas (EBP), estava sendo incorporada pelos estudos contemporâneos de AO no país. Dessa maneira, o trabalho das autoras, suas citações, os trabalhos que o citam, e os dispositivos de inscrição (metapesquisas, pesquisa bibliográfica, análise de outros trabalhos relacionados), pode ser encarado como um caminho inicial a partir do qual se busca compreender o conhecimento sobre aprendizagem e cultura organizacional no Brasil. Desde já, os autores deste artigo reconhecem os limites impostos pela escolha do texto a partir do qual a pesquisa se desenvolve. Contudo, também há intenção de abrir possibilidades para futuros estudos que se utilizem do método da inscrição literária para a análise de outros textos, sejam estes produzidos em diferentes espaços e épocas, relacionados a outros métodos, técnicas e/ou materialidades. Espera-se que, assim, seja possível ressignificar esse debate, de modo a incrementar e tornar mais robusta a discussão sobre o tema aqui abordado.

\section{DESCREVENDO O CAPÍTULO EM ANÁLISE: A(S) CULTURA(S) NA APRENDIZAGEM ORGANIZACIONAL}

Elaborado por Antonello e Azevedo (2011) para compor a coletânea Aprendizagem organizacional no Brasil, o capítulo intitulado "Aprendizagem organizacional: explorando o terreno das teorias culturais e das teorias baseadas em práticas" representa uma tentativa de problematizar os diálogos e as fronteiras entre as teorias culturais, Os EBP e a AO. 
Para demonstrar a pertinência de seus argumentos, o capítulo recupera os estudos fundadores e clássicos do campo de OLKC, buscando confirmar o fato de que a tradição da disciplina de AO constituiu diálogo direto com a Administração científica da primeira metade do século XX. Isso posto, facilitar a aquisição de conhecimentos no mundo dos negócios seria mais uma vantagem competitiva das organizações. Para as autoras, contudo, a partir da década de 1990, surgiu a necessidade de relacionar a aprendizagem individual e organizacional aos processos sociais, transformando, assim, os pressupostos teórico-metodológicos da disciplina. Com base em Gherardi (2006), as autoras postulam que se trata de um momento no qual o conhecimento passou a ser reconhecido enquanto processo social pelo campo da $\mathrm{AO}$, e não como uma mercadoria que pode ser transferida. Em consonância com os ensinamentos de Bruno Latour e Steve Woolgar, fica evidente que os enunciados emitidos pelas autoras estão carregados de documentos e de modalidades que constituem, em si, seu aval.

Nada obstante, Antonello e Azevedo (2011) analisam os capítulos 1 e 2 da obra Aprendizagem organizacional no Brasil - capítulos estes redigidos por Claudia Simone Antonello e Arilda Schmidt Godoy, anteriormente publicados em 2009 e 2010, e que contam com mais de 100 citações - para afirmar que a abordagem da administração científica tradicional marca os estudos de AO no Brasil, apesar do reconhecimento do caráter processual, social e cultural do campo de OLKC. Isso permite que Antonello e Azevedo (2011), mesmo reconhecendo a facticidade dos trabalhos contemporâneos que assumem o conhecimento como situado em atividades realizadas em contextos materiais e sociais, afirmem que a visão culturalista é subutilizada no Brasil.

Então, as autoras se dedicam a situar as discussões iniciadas sobre aprendizagem e cultura nas organizações. Em um primeiro momento, o capítulo resgata as concepções das cinco ramificações ideais das teorias culturais de Reckwitz (2002), a saber: (1) mentalismo objetivista de Ferdinand de Saussure e Claude Lévi-Strauss; (2) mentalismo subjetivista de Alfred Schutz; (3) perspectiva textualista de Michel Foucault, Clifford Geertz e Niklas Luhmann; (4) intersubjetivismo de Jürgen Habermas; e (5) teoria da prática de Pierre Bourdieu, Anthony Giddens, Bruno Latour e Theodore R. Schatzki. Com base nesse levantamento, o capítulo analisado sugere que cada uma das ramificações ideais apresenta diferentes concepções sobre a localização do social, do corpo, da mente, das coisas, da estrutura, do processo e do agente. Entretanto, as autoras identificam um ponto comum: "vários desses modelos culturalistas trabalham com a ideia de prática" (ANTONELLO e AZEVEDO, 2011, p. 98).

Em vista disso, Antonello e Azevedo (2011) sugerem que pesquisadores interessados nas perspectivas culturais e sociopráticas de AO podem buscar inspiração nos trabalhos de Lave e Wenger (1991), Brown e Duguid (1991), Cook e Yanow (1993), Nicolini e Meznar (1995), Gherardi, Nicolini e Odella (1998), Yanow (2000), Gherardi (2000) e Strati (2007). Dessa acumulação de citações de trabalhos com enfoques alternativos (situados, culturais e práticos), que nem sempre trabalham com visões convergentes, mas que utilizam a noção de prática, as autoras geram um efeito de objetividade para a utilização dos EBP nos Estudos Organizacionais sobre conhecimento e aprendizagem.

A Figura 2 representa em diagrama as citações feitas por Antonello e Azevedo (2011), mostrando as diferentes perspectivas abordadas ao longo do texto. Por meio dela, pode-se compreender os caminhos trilhados por Antonello e Azevedo (2011) para conquistar uma existência relativamente autônoma para o capítulo e, ao mesmo tempo, fundamentar a construção (teórico-conceitual) objetiva e real dos EBP para a investigação de processos de AO. 
Figura 2

Conhecimento sobre o conhecimento de aprendizagem, prática e cultura nas organizações

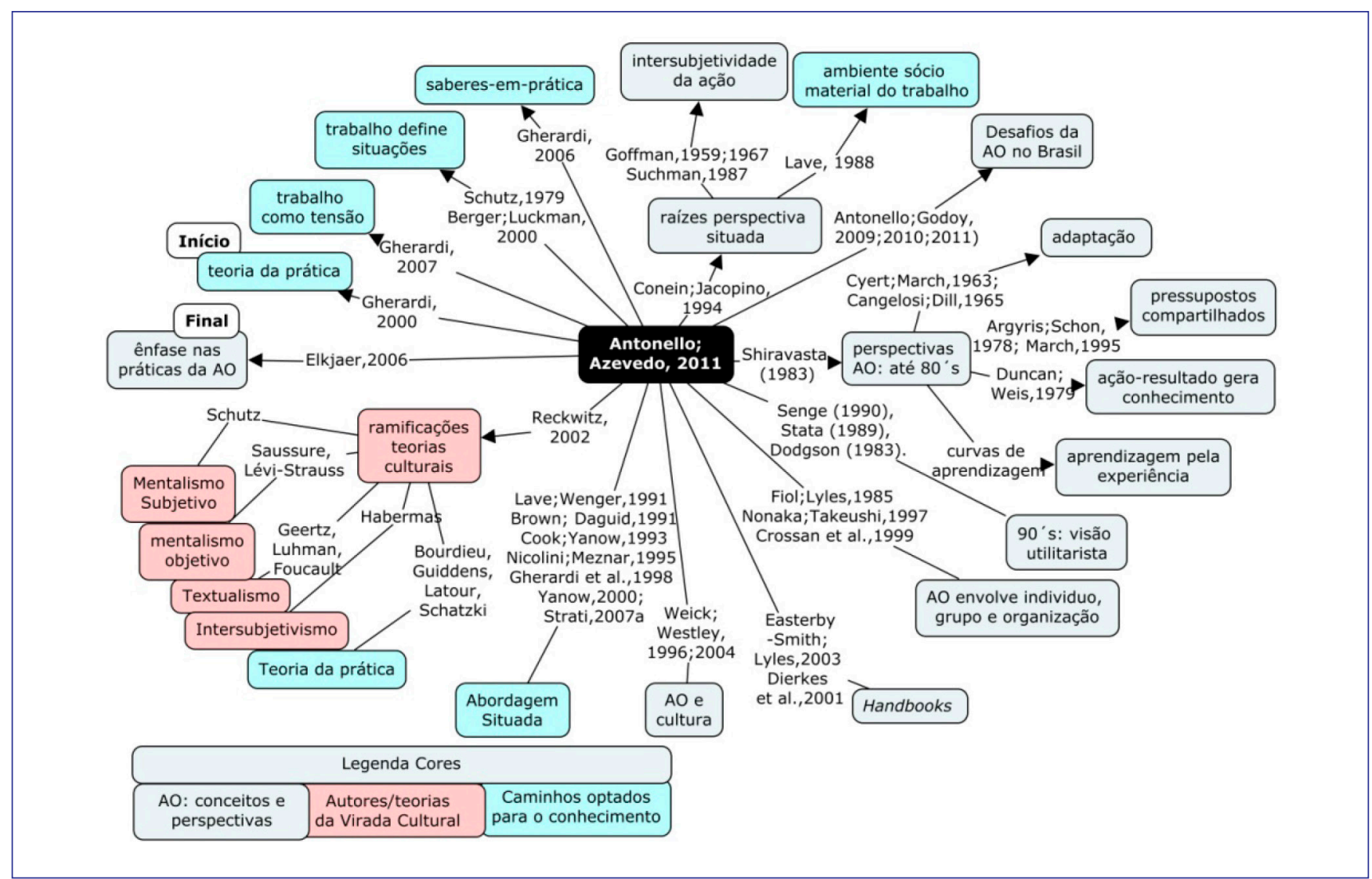

Fonte: Elaborada pelos autores.

Na próxima seção, articulam-se artigos que citaram o trabalho de Antonello e Azevedo (2011), visando ao envolvimento, na análise, dos desempenhos "dos inscritores, dos documentos, dos enunciados, assim como das reações que provocou [o trabalho dessas autoras]" (LATOUR e WOOLGAR, 1997, p. 90). Com isso, a partir da extensão da rede representada pelo capítulo "Aprendizagem organizacional: explorando o terreno das teorias culturais e das teorias baseadas em práticas", espera-se desenvolver o debate no campo sobre aprendizagem e cultura organizacional no Brasil.

\section{INSCREVENDO A CULTURA NA APRENDIZAGEM ORGANIZACIONAL: PRODUÇÕES A PARTIR DO TEXTO ANALISADO}

O trabalho de Antonello e Azevedo (2011) faz parte de outras operações inerentes à área dos Estudos Organizacionais brasileiros. Esse fato fica evidente se considerarmos que, desde o lançamento do livro Aprendizagem organizacional no Brasil até setembro de 2015, o estudo de Antonello e Azevedo (2011) foi referenciado mais de 20 vezes por outros 7 artigos, segundo levantamento feito no Google Acadêmico em 30 de setembro de 2015. Assim, uma vez que o propósito deste trabalho é realizar uma análise em rede do capítulo, consideram-se igualmente os efeitos que esse conhecimento segue produzindo. A seguir são apresentados os trabalhos que citam Antonello e Azevedo (2011), a começar pela pesquisa que mais recentemente referenciou o trabalho dessas autoras. 
Dentre os sete artigos que fazem referência a Antonello e Azevedo (2011), o trabalho de Souza, Tanaka, Dias et al. (2014) tem por objetivo analisar a aprendizagem de gerentes e identificar diferenças entre gestores com distintas formações. Os autores identificam estilos de aprendizagem díspares e mapeiam a relação existente entre aprendizagem, experiência e relacionamento. O trabalho desses autores utiliza Antonello e Azevedo (2011) para assumir que a aprendizagem formal e a informal não são inerentes ou superiores uma à outra, estando essas formas de aprendizagem inter-relacionadas. Já no que diz respeito ao modo como o artigo adota a noção de cultura, Souza, Tanaka, Dias et al. (2014, p. 3) assumem que a aprendizagem gerencial - formal e informal - situa-se em contexto organizacional, social e cultural no ambiente em que a aprendizagem ocorre. Nesse sentido, a cultura aparece como uma das dimensões (contexto, economia, tecnologia) que influenciam a aprendizagem e o modo como os colaboradores trabalham, trocam ideias e experiências nas organizações.

Já Sawitzki e Antonello (2014) objetivam compreender o(s) processo(s) de AO a partir das práticas de produção dos espetáculos teatrais de uma organização não governamental esteadas na perspectiva cultural. As autoras utilizam Antonello e Azevedo (2011) para dialogar com a noção de Gherardi (2001, p. 132) - que advoga em favor da produção conjunta de sujeitos e objetos na prática situada - de que o contexto se (re)produz constantemente em quadros situacionais diversos. Reconhece-se, assim, que a(s) interação(ões) situada(s) pode $(\mathrm{m})$ ser mediada(s) pelo corpo, pelas tecnologias, pelos objetos, pela materialidade, pela linguagem, pelas relações sociais. As autoras igualmente utilizam o trabalho de Antonello e Azevedo (2011) no tópico que diz respeito ao método e delineamento da pesquisa, junto com Gherardi (2006), para afirmar que a perspectiva cultural demanda um posicionamento epistemológico interpretativista.

Outro texto que faz referência ao capítulo do livro Aprendizagem organizacional no Brasil, analisado por este artigo, é o estudo de caso de Ruas, Raupp, Becker et al. (2014) no setor bancário para entender a contribuição da aprendizagem organizacional na dinâmica das competências organizacionais. O tópico elaborado por Antonello e Azevedo (2011) é empregado no referencial teórico, em uma seção destinada a mapear e analisar a polissemia de significados e perspectivas dos estudos de aprendizagem organizacional. Em específico, Ruas, Raupp, Becker et al. (2014, p. 623), ao tratar dos níveis de aprendizagem - individual, grupal e organizacional - colocam que "Antonello e Azevedo (2011) entendem que a expressão Aprendizagem Organizacional pode ser expressa por diferentes narrativas, o que abre espaço para diferentes compreensões, sejam elas práticas, teóricas, profissionais ou cotidianas". Assim, Ruas, Raupp, Becker et al. (2014, p. 623) conceituam a AO como o "desenvolvimento de conhecimentos sobre a base das relações ação-resultado", com base no trabalho das autoras, uma vez que permite trabalhar "a aprendizagem no nível organizacional [...] como um processo gerador de conhecimentos que se difunde na organização e é integrado às práticas de trabalho ou rotinas organizacionais".

Bertolin, Cappelle e Brito (2014) aproveitam Antonello e Azevedo (2011) para confirmar a percepção própria de que a interação situada é fonte de conhecimento sensível por ser mediada pelo corpo. Considera-se que o artigo no qual as autoras são citadas tem como objetivo geral apresentar uma "ampliação" das metodologias de AO. Dessa forma, infere-se que estes autores fizeram referência ao estudo de Antonello e Azevedo (2011) para estender a relação entre "interação situada" e "corpo", e, ao mesmo tempo, para refletir sobre a importância da corporeidade e do conhecimento estético no avanço teórico da AO. Bertolin, Cappelle e Brito (2014) fazem menção à palavra cultura para relevar que contextos organizacionais podem favorecer (ou não) os processos de aprendizagem. Nesse sentido, os aspectos culturais aparecem como mediadores da aprendizagem em contexto de prática organizacional. É importante notar que o texto de Bertolin, Cappelle e Brito (2014) é citado por outros dois artigos (LOPES, SOUZA e IPIRANGA, 2014; GANEM, 2014). Ainda assim, o trabalho de Lopes, Souza e Ipiranga (2014), que fez menção a Bertolin, Cappelle e Brito (2014), é referenciado por Lopes, Ipiranga e Silva Junior no ano de 2015.

Um ano antes, Bertolin, Zwick e Brito (2013) citaram o artigo de Antonello e Azevedo (2011) em diálogo com os textos de Gherardi $(2000 ; 2009)$ e Gherardi e Nicolini (2002), em dois momentos na sessão de fundamentação teórica. Primeiro, para assumir a AO como situada e socialmente construída e, em seguida, para reificar a importância das atividades das comunidades organizacionais (lócus da produção do conhecimento). Dessa maneira, Bertolin, Zwick e Brito (2013) discutem a AO no serviço público e analisam sua configuração a partir de elementos sociais que constituem as práticas de trabalho. Uma vez que o artigo considera a aprendizagem como socialmente construída, destaque é atribuído à dimensão social, prática e interacionista do processo de construção do conhecimento. Dito de outra forma, a cultura (aspectos culturais) faz a mediação das circunstâncias organizacionais que podem facilitar ou dificultar a aprendizagem. Outrossim, Bertolin, Zwick e Brito (2013) é citado por: (1) dois outros artigos (ROSA, MARTINEZ e BALASSIANO, 2015; CASTRO, BRITO e VARELA, 2014); (2) duas dissertações apresentadas em 2014 ao mestrado profissional em Administração da Universidade Potiguar (UNP) (preparada por Cíntia G. Costa, orientada pela Profa. Dra. Lydia M. P. Brito) e da Fundação Pedro Leopoldo (elaborada por Vânia H. T. Vidal, 
orientada pela Profa. Dra. Ester E. Jeunon); e (3) Kely C. M. de Paiva e Flaviana A. de Pádua Carvalho, em uma disciplina de gestão de serviços públicos da Universidade Federal de Minas Gerais (UFMG).

Silva, Godoy e Hanashiro (2013), que têm por objetivo discutir a relação entre aprendizagem e cultura nas organizações, fazem alusão ao trabalho de Antonello e Azevedo (2011) para assumir que a perspectiva cultural da AO tem sido pouco explorada na produção acadêmica brasileira, e, por conseguinte, para justificar a realização do estudo. $O$ artigo descreve o conhecimento sobre, bem como a inter-relação entre, $\mathrm{AO}$ e cultura organizacional no Brasil, como imprescindíveis para o desempenho e a permanência das organizações em um mundo globalizado e mutável, sugerindo que pesquisas práticas (profundas e comparativas) devem promover o diálogo entre cultura e aprendizagem em diferentes contextos de prática organizacional.

Por último, o estudo de Rodrigues e Azevedo (2012) faz referência ao trabalho das autoras para problematizar a necessidade de conhecer melhor a ação e as atividades humanas, com o fim de posicionar a abordagem baseada em prática como perspectiva excepcional para estudar aprendizagem nas organizações. Empiricamente, o trabalho faz alusão aos desenvolvimentos de Antonello e Azevedo (2011) para descrever o processo de formação de açougueiros em relação aos diversos jeitos de ser dos veteranos e para relatar como o conhecimento em ação faz com que um bife bem cortado tenha significados diferentes (d)entre as diferentes filiais. Sobre a relação do artigo com a noção de cultura, Rodrigues e Azevedo (2012, p. 5) reconhecem que o estudo de práticas sociais ocorre em um contexto cultural e histórico e que o saber é um fenômeno social e cultural para explorar conhecimentos "menos intencionais, menos instrumentais e mais reflexivos".

Sintetizando, dentre esses 7 artigos que utilizam o trabalho de Antonello e Azevedo (2011): (1) 4 são casos práticos que adotam a perspectiva (social, cultural, prática) situada da AO descrita pelas autoras; (2) 1 estudo parte dessa perspectiva socioprática para ampliar metodologias e epistemologias dos estudos de AO; (3) 1 artigo reflete sobre pontos de intersecção entre AO e cultura organizacional; e (4) por fim, 1 adota a perspectiva cultural da AO. Desse modo, argumenta-se que, no Brasil, a relação entre aprendizagem e cultura nas organizações pode ser compreendida (iniciada, problematizada, estendida, adicionada, emprestada) a partir dos estudos citados no capítulo escrito por Antonello e Azevedo (2011) e dos estudos que citam as autoras. A rede temporária - que congrega universidades, pesquisas, objetos de estudo empírico, teorias, conceitos, perspectivas - tecida a partir de Antonello e Azevedo (2011), que dá mostras sobre o modo como determinadas concepções de cultura vêm sendo abordadas na disciplina de AO no Brasil, pode ser visualizada na Figura 3.

Figura 3

\section{Rede temporária tecida a partir de textos que citam Antonello e Azevedo (2011)}

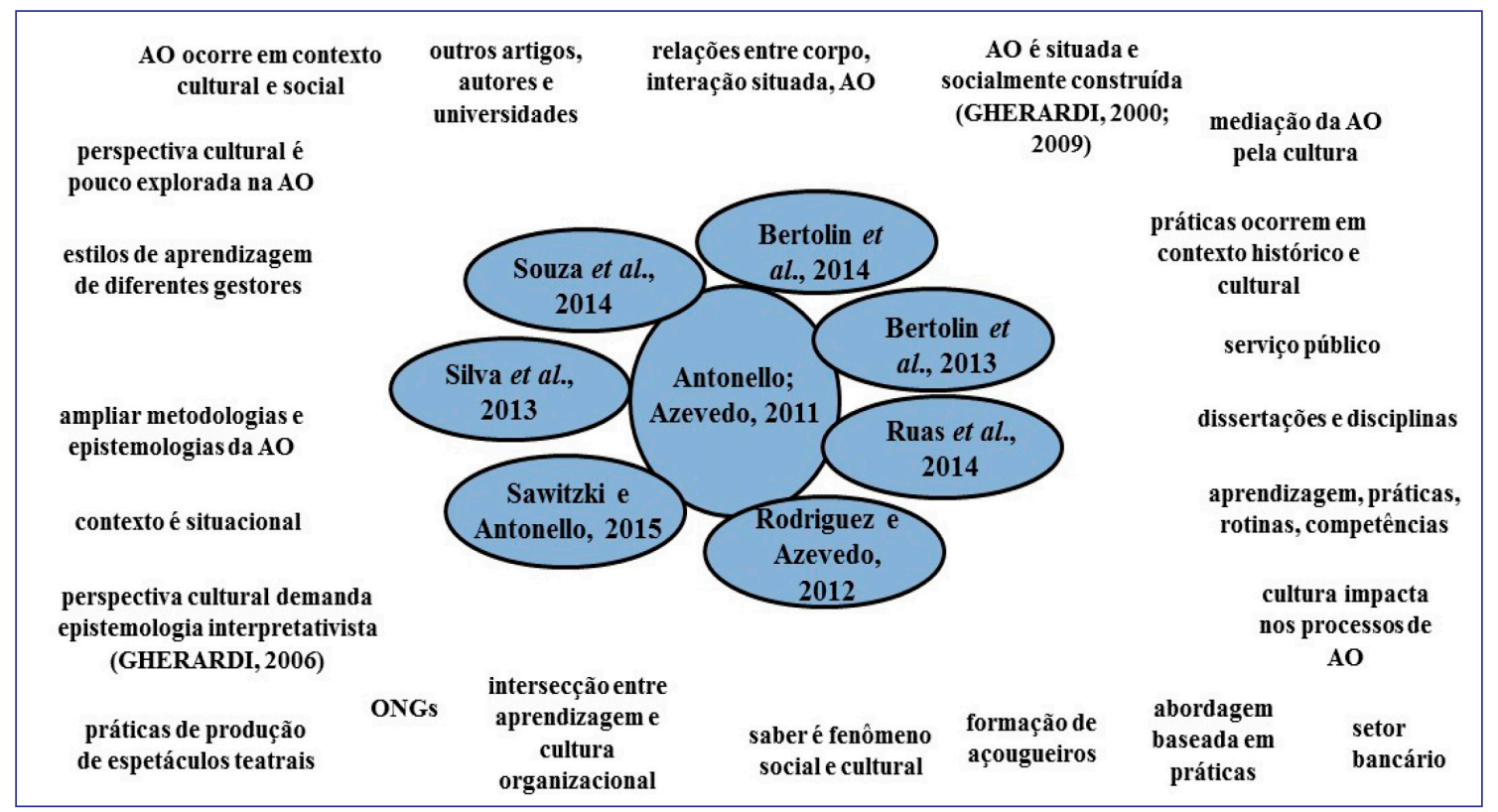

Fonte: Elaborada pelos autores. 
No próximo item, visando a concluir o argumento aqui desenvolvido, analisa-se de que forma o movimento de incorporação de determinadas perspectivas sobre a cultura por parte da disciplina de AO no Brasil permitiu e facilitou fluxos intelectuais entre as Ciências Sociais e a Administração. Vale observar que tais perspectivas sobre a cultura por parte da disciplina de AO no Brasil foram compreendidas a partir da descrição da rede desempenhada pelo e a partir do capítulo escrito por Antonello e Azevedo (2011), bem como da construção social e histórica do campo de OLKC empreendida no terceiro tópico deste artigo.

\section{À GUISA DE CONCLUSÃO: O CONHECIMENTO SOBRE O CONHECIMENTO NA ÁREA}

Este artigo descreve o modo como determinadas concepções de cultura vêm sendo abordadas no campo de AO, a partir do uso da inscrição literária na análise de um capítulo de uma coletânea que trata de AO no Brasil. Observa-se, a partir da análise empreendida, que a noção de cultura é tomada e utilizada pelo campo brasileiro de AO, em grande parte, para demonstrar explicitamente o processo social da aprendizagem nas organizações como preeminente (EASTERBY-SMITH e LYLES, 2003; 2011).

Contudo, a partir da rede da qual Antonello e Azevedo (2011) fazem parte, identificaram-se, ainda, outros estudos associados (opostos, somados, contrapostos) que relacionam a noção de cultura com a AO diferentemente, oferecendo e diferenciando possíveis perspectivas para trabalhar aprendizagem e cultura nas organizações brasileiras. Dessa forma, a partir da obra analisada e da rede que a compõe, percebe-se a construção de uma agenda polissêmica de usos e interpretações do termo cultura.

Tal agenda polissêmica constrói-se a partir de diversas apropriações da noção de cultura, em movimentos que podem ser, inclusive, compreendidos a partir das próprias reflexões de Antonello e Azevedo (2011). Nesse sentido, a partir da constituição do campo de OLKC na década de 1960, a disciplina de AO aproximou-se do conceito de cultura em um diálogo que se foi transformando empírica e metodologicamente ao longo do tempo.

A aproximação inicial ao conceito de cultura, que, corresponde, como foi discutido neste texto, ao próprio surgimento do campo científico da $\mathrm{AO}$, tem por premissa a relação de aspectos culturais com elementos (sistemas) comportamentais e cognitivos da organização. Tal conceito se aproxima de uma concepção conhecida nas ciências sociais como universalista, a partir de definições não necessariamente normativas, mas sim descritivas e objetivas, em que a cultura é concebida como expressão da totalidade da vida do sujeito (CUCHE, 2002), tratando-se do comportamento aprendido, em oposição a um comportamento inato (LARAIA, 2009). A cultura, nessa concepção, seria entendida como um sistema de conhecimento (LARAIA, 2009).

Depois disso, tendo por pano de fundo reapropriações construídas em termos mais amplos (Estudos Organizacionais de forma geral), a partir de discussões travadas no seio das Ciências Sociais, a abordagem simbólica faz-se presente no campo. Aspectos culturais tornam-se subjacentes a uma lógica simbólica de estudo e análise das organizações. Segundo essa perspectiva, a cultura passa a ser vista como fenômeno interpretável, a partir do clássico conceito gestado na Escola Americana da Antropologia, que a percebe como uma teia de significados construída pelos sujeitos (GEERTZ, 1989). Dentro de uma perspectiva dita textualista, entende-se que estudar a cultura é interpretar um código de símbolos partilhados pelos membros da cultura, lendo um texto cultural (LARAIA, 2009).

Atualmente, há um novo movimento sinalizado por Antonello e Azevedo (2011), em consonância com a chamada virada prática (SCHATZKI, KNORR-CETINA e SAVIGNY 2006) nos estudos sobre organizações, no qual se percebe uma aproximação da AO em relação aos estudos sobre prática, com ênfase em aspectos materiais e performativos. Dessa maneira, muitas dessas pesquisas jogam luzes sobre o cotidiano organizacional, na busca por compreender as organizações como elas ocorrem (SCHATZKI, 2006). Nesse caminho, alguns autores recomendam, inclusive, o uso de métodos advindos da própria Antropologia, como a etnografia (GHERARDI, 2013). Assim, o conceito de cultura permitiu um movimento no qual, em um primeiro momento, os estudos de $\mathrm{AO}$ atentassem aos elementos comportamentais e cognitivos, depois aos simbólicos e, hoje, à ideia de prática.

Esse movimento de incorporação de determinadas perspectivas sobre a cultura por parte dessa disciplina de AO, contudo, não gerou um movimento linear de ida, sem volta, pela trilha das práticas. Evidencia-se, pois, a não linearidade da produção de fatos científicos, em relações que, no caso estudado, ofereceram alternativas e caminhos, e não necessariamente impossibilidades, para a epistemologia do conhecimento - utilitarista, estruturalista, materialista, comportamental, cognitiva, psicológica, prática, simbólica, sistêmica, histórica, antropológica - sobre aprendizagem nas contemporâneas organizações ao redor do globo. 
Ao refletir sobre o potencial analítico da inscrição literária, este artigo procurou traçar um caminho alternativo a partir do qual se buscou compreender o processo de construção do conhecimento sobre cultura organizacional em um campo específico do conhecimento no Brasil. Desse modo, sugere-se que seja compreendido como uma iniciativa frutífera e interessante, ainda que mediada pela seleção de um texto particular e limitada às condições objetivas impostas por essa própria escolha. Portanto, antes mesmo de encerrar qualquer controvérsia em torno do debate aqui travado, esta pesquisa tem a pretensão de abrir possibilidades para futuros estudos que se utilizem do método da inscrição literária para a análise de outros textos ou contextos de produção do conhecimento científico neste ou em outros campos.

Assim, espera-se, com este estudo, ter apresentado possíveis caminhos para o conhecimento sobre aprendizagem e cultura organizacional, ao menos até que os enunciados postulados por este artigo sejam (re)avaliados ou até que a evolução histórica deste campo de estudos represente diferentes modos de associação e apropriação da noção de cultura pelos estudos de aprendizagem e conhecimento organizacional no Brasil e no mundo. Este estudo insere-se nessa rede e, acredita-se, efetiva uma possível trilha para pesquisadores organizacionais de toda sorte, dado que reconhece que, para a ciência, o caminho é, em si, o conhecimento (LATOUR, 2007). 


\section{REFERÊNCIAS}

ALVES, P. Introdução. In: ALVES, P. (Org.). Cultura: múltiplas leituras. Bauru, SP: Edusc, 2010. 15-19 p.

ALVESSON, M. Organizations as rhetoric: knowledge-intensive firms and the struggle with ambiguity. Journal of Management Studies, v. 30, p. 997-1015, 1993.

ANTAL, A. B. et al. Organizational learning and knowledge: reflections on the dynamics of the field and challenges for the future. In: DIERKES, M. et al. (Org.). Handbook of organizational learning and knowledge. Oxford: Oxford University Press, 2001. 921-939 p.

ANTONELLO, C. S. Estudo dos métodos e posicionamento epistemológico na pesquisa de aprendizagem organizacional, competências e gestão do conhecimento. In: ENCONTRO ANUAL DA ANPAD, 26.; 2002, Salvador. Anais... Salvador: ANPAD, 2002.

ANTONELLO, C. S. A metamorfose da aprendizagem organizacional: uma revisão crítica. In: RUAS, R.; ANTONELLO, C. S.; BOFF, L. H. (Org.). Aprendizagem organizacional e competências. Porto Alegre: Bookman, 2005. 12-33 p.

ANTONELLO, C. S.; AZEVEDO, D. Aprendizagem organizacional: explorando o terreno das teorias culturais e das teorias baseadas em práticas. In: ANTONELLO, C. S.; GODOY, A. S. Aprendizagem organizacional no Brasil. Porto Alegre: Bookman, 2011. 87-111 p.

ANTONELLO, C. S.; GODOY, A. S. A encruzilhada da aprendizagem organizacional: uma visão multiparadigmática. Revista de Administração Contemporânea, v. 14, n. 2 p. 310-332, 2010.

ANTONELLO, C. S.; GODOY, A. S. Aprendizagem organizacional no Brasil. Porto Alegre: Bookman, 2011.

ARAÚJO, J. B. Administrative reorganizations: myths and prospects. Rev. Adm. Pública, v. 15, n. edição extra, p. 4-32, 1981.

ARGYRIS, C.; SCHON, D. A. Theory in practice: increasing professional effectiveness. San Francisco, CA: Jossey-Bass, 1974.

ARGYRIS, C.; SCHON, D. Organizational learning: a theory of action approach. Reading, MA: Addision Wesley, 1978.

BASTOS, A. V. B.; GONDIM, S. M. G.; LOIOLA, E. Aprendizagem organizacional versus organizações que aprendem: características e desafios que cercam essas duas abordagens de pesquisa. Revista de Administração, v. 39, n. 3, p. 220-230, 2004.

BERTOLIN, R. V. et al. Aprendizagem organizacional socioprática no serviço público: um estudo de caso interpretativo. Rev. Adm. Pública, v. 47, n. 2, p. 493-513, 2013.

BERTOLIN, R. V. et al. Corporeidade e estética na aprendizagem organizacional: insights emergentes. Revista de Administração Mackenzie, v. 15, n. 2 , p. 15-37, 2014.

BLACKER, F. Knowledge, knowledge work and organizations: an overview and interpretation. Organization Studies, v. 6, n. 6, p. 1021-1046, 1995.

BOTELHO, D. Organizações de aprendizagem. São Paulo: Fundação Getulio Vargas, 1997.
BOURDIEU, P. Os usos sociais da ciência: por uma sociologia clínica do campo científico. São Paulo: Ed. Unesp, 2004.

BRITO, M. J.; BRITO, V. G. P. Aprendizagem nas organizações: paradigmas de análise, teoria e cultura organizacional. Organizações e Sociedade, v. 4, n. 10, p. 15-41, 1997.

BROWN, J. S.; DUGUID, P. Organizational learning and communities-of-practice: toward a unified view of working, learning, and innovation. Organization Science, v. 2, n. 1, p. 40-57, 1991.

BRYAN, S. E. A melhoria da produção no Brasil. Revista de Administração de Empresas, v. 1, n. 2, p. 27-55, 1961.

CANGELOSI, V. E.; DILL, W. R. Organizational learning: observations toward a theory. Administrative Science Quarterly, v. 10, n. 2, p. 175-203, 1965.

CARAVANTES, G. R.; PEREIRA, M. J. L. Aprendizagem organizacional versus estratégia de mudança organizacional planejada: um confronto crítico. Rev. Adm. Pública, v. 15, n. 2, p. 23-44, 1981.

CASTRO, A. B. C.; BRITO, L. M. P.; VARELA, J. H. S. Quem dissemina saber, aprende com o conhecimento que constrói? Um estudo de múltiplos casos em organizações públicas do Nordeste do Brasil. Perspectivas em Gestão e Conhecimento, v. 4, n. 2, p. 126-146, 2014.

CAVEDON, N. R. Antropologia para administradores. Porto Alegre: Ed. UFRGS, 2003.

CLEGG, S. R.; HARDY, C.; NORD, W. R. (Eds.). Handbook of organisational studies. London: Sage, 1996.

CLEGG, S. R. et al. (Eds.). The Sage handbook of organization studies. London: Sage, 2006.

COOK, S. D. N.; YANOW, D. Culture and organizational learning. Journal of Management Inquiry, v. 2, n. 4, p. 373-390, 1993.

COSTA, C. G. Aprendizagem no trabalho: uma análise da percepção de gestores públicos. Dissertação de mestrado apresentada ao Programa de Pós-Graduação em Administração, por meio do Mestrado Profissional em Administração da Universidade Potiguar - UnP, como requisito para obtenção do título de mestre, na área de concentração Gestão Estratégica de Pessoas. Natal, RN, 2014.

CUCHE, D. A noção de cultura nas ciências sociais. Bauru, SP: Edusc, 2002.

CUNHA, M. P. Introdução. In: ANTONELLO, C. S.; GODOY, A. S. Aprendizagem organizacional no Brasil. Porto Alegre: Bookman, 2011. $x i-x x v p$.

CYERT, R. M.; MARCH, J. G. A behavioral theory of the firm. Englewood Cliffs: Prentice-Hall, 1963.

DAVENPORT, T. H.; PRUSAK, L. Working knowledge: how organizations manage what they know. Cambridge, MA: Harvard Business School Press, 1998.

DERRIDA, J. Of grammatology. Baltimore, MD: Johns Hopkins University, 1976.

DIERKES, M. et al. (Org.). Handbook of organizational learning and knowledge. Oxford: Oxford University Press, 2001. 
DOYLE, M. L.; VERSIANI, A. F. A produção acadêmica nacional em aprendizagem organizacional: uma década depois da publicação de Loyola e Bastos (2003). In: ENCONTRO ANUAL DA ANPAD, 37.; 2013, Rio de Janeiro. Anais... Rio de Janeiro: ANPAD, 2013.

EASTERBY-SMITH, M.; ARAUJO, L. Aprendizagem organizacional e organizações de aprendizagem: desenvolvimento na teoria e na prática. São Paulo: Atlas, 2001.

EASTERBY-SMITH, M.; LYLES, M. (Org.). Handbook of organizational learning and knowledge management. London: Blackwell, 2003.

EASTERBY-SMITH, M.; LYLES, M. (Org.). Handbook of organizational learning and knowledge management. Chichester: Wiley, 2011.

EPPLE, D.; ARGOTE, L.; DEVADAS, R. Organizational learning curves: a method for investigating intra-plant transfer of knowledge acquired through learning by doing. Organization Science, v. 2, n. 1, p. 58-70, 1991.

FACHIN, R. C.; SILVA, L. C. M. O comportamento político do dirigente de empresa estatal na formulação de estratégias. Revista de Administração de Empresas, v. 24, n. 4, p. 243-252, 1984.

FIGUEIREDO, P. N. Tecnologia e gestão empresarial inovadora. Caderno de Gestão Tecnológica. São Paulo, 1996.

FISCHER, T. et al. Reconfigurações organizacionais e transformações gerenciais em organizações de serviços: a saga da Telebahia. Rev. Adm. Pública, v. 30, n. 3, p. 38-52, 1996.

FLEURY, A. Gestão de tecnológica na empresa industrial brasileira. Revista de Administração da Universidade de São Paulo, v. 22, n. 4, p. 3-13, 1987.

FLEURY, M. T. L. Aprendendo a mudar: aprendendo a aprender. Revista de Administração, v. 30, n. 3, p. 5-11, 1995.

FLEURY, M. T.; FLEURY, A. Aprendizagem e inovação organizacional. 2. ed. São Paulo: Atlas, 1997.

FLEURY, M. T. L.; FLEURY, A. Aprende-se com as empresas japonesas? Estudo comparativo entre empresas brasileiras e mexicanas. Revista de Administração Contemporânea, v. 2, n. 1, p. 7-26, 1998.

FREITAS, M. E. F. Cultura organizacional: evolução e crítica. São Paulo: Cengage Learning, 2007.

GANEM, M. Inovando em comunidades tradicionais com base na brincadeira. Revista Interdisciplinar de Gestão Social, v. 3, n. 1, p. 119-120, 2014.

GARRATT, B. The learning organization. London: Fontana, 1987.

GEERTZ, C. A interpretação das culturas. Rio de Janeiro: LTC, 1989.

GHERARDI, S. Practice-based theorizing on learning and knowing in organizations. Organization, v. 7, n. 2, p. 211-224, 2000.

GHERARDI, S. From organizational learning to practice-based knowing. Human Relations, v. 1, n. 54, p. 131-139, 2001.

GHERARDI, S. Organizational knowledge: the texture of workplace learning. London: Blackwell, 2006.

GHERARDI, S. Introduction: the critical power of the practice lens. Management Learning, v. 40, n. 2, p. 115-128, 2009.
GHERARDI, S. How to conduct a practice-based study: problems and methods. Cheltenham: Edward Elgar, 2013.

GHERARDI, S.; NICOLINI, D. Learning in a constellation of interconnected practices: canon or dissonance? Journal of Management Studies, v. 39, n. 4, p. 419-436, jun. 2002.

GHERARDI, S.; NICOLINI, D.; ODELLA, F. Toward a social understanding of how people learn in organizations: the notion of situated curriculum. Management Learning, v. 29, n. 3, p. 273-297, 1998.

GUIMARÃES, T. A. et al. A rede de programas de pós-graduação em administração no Brasil: análise de relações acadêmicas e atributos de programas. Revista de Administração Contemporânea, v. 13, n. 4, p. 564-582, 2009.

HUBER, G. P. Organizational learning: The contributing processes and the literatures. Organization Science, v. 2, n. 1, p. 88-115, 1991.

KNORR-CETINA, K. The Manufacture of Knowledge: An Essay on the Constructivist and Contextual Nature of Science. Oxford: Permagon press, 1981.

LARAIA, R. B. Cultura: um conceito antropológico. Rio de Janeiro: Jorge Zahar, 2009.

LATOUR, B. A textbook case revisited: knowledge as mode of existence. In: HACKETT, E. J. et al. (Eds.). The handbook of science and technology studies. Cambridge, MA: The MIT Press, 2007. 83-112 p.

LATOUR, B.; WOOLGAR, S. A vida de laboratório: a produção dos fatos científicos. Rio de Janeiro: Relume Dumará, 1997.

LAVE, J.; WENGER, E. Situated learning: legitimate peripheral participation. Cambridge: Cambridge University Press, 1991.

LOIOLA, E.; BASTOS, A. V. B. A produção acadêmica sobre aprendizagem organizacional no Brasil. Revista de Administração Contemporânea, v. 7, n. 3, p. 181-201, 2003.

LOPES, L. L. S.; IPIRANGA, A. S. R.; SILVA JÚNIOR, J. J. da COMPREENSÃO EMPÁTICA E AS POSSÍVEIS CONTRIBUIÇÕES PARA A PESQUISA NOS ESTUDOS ORGANIZACIONAIS: REFLEXÕES A PARTIR DA ESTÉTICA. V Colóquio Internacional de Epistemologia e Sociologia da Ciência da Administração. Florianópolis, SC, Brasil, Março, 2015.

LOPES, L. L. S.; SOUZA, E. M.; IPIRANGA, A. S. R. Desvelando as categorias estéticas na organização de um pequeno restaurante. Revista Interdisciplinar de Gestão Social, v. 3, n. 1, p. 207-222, 2014.

MARCH, J. G.; OLSEN, J. P. (Eds.). Ambiguity and choice in organisations. Bergen: Universitetsforlaget, 1976.

MARTIN, J.; FROST, P. Jogos de guerra da cultura organizacional: a luta pelo domínio intelectual. In: CLEG, S.; HARDY, C.; NORD, W. Handbook de estudos organizacionais. São Paulo: Atlas, 2001. v. 2. 219-251 p.

MITROFF, I. I.; EMSHOFF, J. R. On strategic assumption-making: a dialectical approach to policy and planning. Academy of Management Review, v. 4, n. 1, p. 1-12, 1979.

MOURA, W. O paradigma frankfurteano: uma alternativa para a psicologia organizacional. Rio de Janeiro: Fundação Getulio Vargas, 1986.

NELSON, P. R.; WINTER, S. An evolutionary theory of economic change. Cambridge, MA: Harvard University Press, 1982. 
NICOLINI, D.; MEZNAR, M. B. The social construction of organizational learning: conceptual and practical issues in the field. Human Relations, v. 48, n. 7, p. 727-746, 1995.

PAIVA, K. C. M.; PÁDUA CARVALHO, F. A. Disciplina: TÓPICOS EM ADMINISTRAÇÃO: GESTÃO DE PESSOAS NO SERVIÇO PÚBLICO Código: CAD 001 Turma: F3 Carga horária: 30 horas/aula Créditos: 02 (dois) Classificação: Optativa Curso: Administração Pré-requisito:-.

PEDLER, M.; BOYDEL, T.; BURGOYNE, J. Towards the learning company. Management Education and Development, v. 20, n. 1, p. 1-8, 1989.

PETTIGREW, A. M. On studying organizational cultures. Administrative Science Quarterly, v. 24, n. 4, p. 570-581, 1979.

PRANGE, C. Aprendizagem organizacional: desesperadamente em busca de teorias. In: EASTERBY-SMITH, M. et al. (Org.). Aprendizagem organizacional e organizações de aprendizagem: desenvolvimento na teoria e na prática. São Paulo: Atlas, 2001. 41-63 p.

RECKWITZ, A. Toward a theory of social practices: a development in culturalist theorizing. European Journal of Social Theory, v. 5, n. 2, p. 243-263, 2002.

RODRIGUES, B.; AZEVEDO, D. Entre facas e chairas: destrinchando a aprendizagem organizacional baseada em prática - um estudo sobre a aprendizagem de açougueiros. In: CONGRESSO NACIONAL DE ADMINISTRAÇÃO E CIÊNCIAS CONTÁBEIS, 3.; 2012, Rio de Janeiro. Anais... Rio de Janeiro: [s.n], 2012.

ROSA, A. O.; MARTINEZ, A. L.; BALASSIANO, M. A face oculta da "ética do medo" no poder público: a ação de servidores públicos na área tributária limitada pelo medo. Organizações e Sociedade, v. 22, n. 72, p. 143-159, 2015.

RUAS, R.; ANTONELLO, C. S. Repensando os referenciais analíticos em aprendizagem organizacional: uma alternativa para análise multidimensional. Revista de Administração Contemporânea, v. 7, n. 3, p. 203-212, 2003.

RUAS, R.; ANTONELLO, C. S.; BOFF, L. H. Os novos horizontes de gestão: aprendizagem organizacional e competências. Porto Alegre: Bookman, 2005.

RUAS, R. et al. A dinâmica das competências organizacionais e a contribuição da aprendizagem: um estudo de caso no setor bancário. Revista Alcance, v. 21, n. 4, p. 612-649, 2014.

SAWITZKI, R. C.; ANTONELLO, C. S. Em cena e nos bastidores: processos de aprendizagem de um grupo de trabalhadores de uma organização do terceiro setor. Revista Alcance, v. 21, n. 4, p. 719-748, 2014.

SCHATZKI, T. R. On organizations as they happen. Organization Studies, v. 27, n. 12, p. 1863-1873, 2006.

SCHATZKI, T. R.; KNORR-CETINA, K.; SAVIGNY, E. V. The practice turn in contemporary theory. New York: Routledge, 2006.
SENGE, P. M. A quinta disciplina: arte, teoria e prática da organização de aprendizagem. São Paulo: Best Seller, 1990.

SHRIVASTAVA, P. A typology of organizational learning systems. Journal of Management Studies, v. 20, n. 1, p. 7-28, 1983.

SILVA, P. T. M.; GODOY, A. S.; HANASHIRO, D. M. M. Cultura organizacional, aprendizagem organizacional e suas relações. In: CONGRESSO ONLINE CONVIBRA - ADMINISTRAÇÃO, 10.; 2013, São Paulo. Anais... São Paulo: Convibra, 2013.

SIMON, B. Education and the social order, 1940-1990. London: Lawrence \& Wishart, 1991.

SMIRCICH, L. Concepts of culture and organizational analysis. Administrative Science Quarterly, v. 28, n. 3, p. 339-358, 1983.

SOUZA, C. R. et al. O processo e os estilos de aprendizagem de gestores de diferentes formações. Revista de Gestão e Secretariado, v. 5, n. 2, p. 72-96, 2014.

STARBUCK, W. H. Learning by knowledge: intensive firms. Journal of management Studies, v. 29, n. 6, p. 713-740, 1992.

STRATI, A. Sensible knowledge and practice-based learning. Management Learning, v. 38, n. 1, p. 61-77, 2007.

TAKAHASHI, A. R. W.; FISCHER, A. L. Debates passados, presentes e futuros da aprendizagem organizacional: um estudo comparativo entre a produção acadêmica nacional e internacional de pessoas. Revista de Administração Mackenzie, v. 10, n. 5, p. 53-76, 2009.

TSANG, E. W. K. Organizational learning and the learning organization: a dichotomy between descriptive and prescriptive research. Human Relations, v. 50, n. 1, p. 73-89, 1997.

VERSIANI, A. F.; FISCHER, A. L. A Aprendizagem organizacional como um campo específico de conhecimento no cenário dos estudos organizacionais. Economia e Gestão, v. 8, n. 8, p. 10-31, 2008.

VIDAL, V. H. T. De modelo burocrático à instituição que aprende: Um Estudo da Mudança Organizacional em Uma IES na Cidade de Barbacena/MG. Dissertação apresentada ao Curso de Mestrado Profissional em Administração, da Fundação Pedro Leopoldo, como requisito parcial para a obtenção do grau de Mestre em Administração. Área de concentração: Gestão da Inovação e Competitividade. Linha de Pesquisa: Inovação e Organizações. Pedro Leopoldo, 2014.

WAGNER, R. A invenção da cultura. São Paulo: Cosac Naify, 2010.

WEICK, K. E.; WESTLEY, F. Organizational learning: affirming an oxymoron. London: Sage, 1996.

YANOW, D. Seeing organizational learning: a cultural view. Organization, v. 7, n. 2, p. 247-268, 2000. 
Bruno Luiz Américo

Mestre em Administração pela Universidade Federal do Paraná (UFPR); Doutorando em Administração na Universidade Federal do Espírito Santo (UFES); Bolsista - CAPES/DS. E-mail: brunolaa@hotmail.com

\section{Fagner Carniel}

Doutor em Sociologia Política pela Universidade Federal de Santa Catarina (UFSC); Professor adjunto no Departamento de Ciências Sociais da Universidade Estadual de Maringá (UEM). E-mail: fagnercarniel@yahoo.com.br

Letícia Dias Fantinel

Doutora em Administração pela Universidade Federal da Bahia (UFBA); Professora adjunta no Departamento de Administração da Universidade Federal do Espírito Santo (UFES). E-mail: leticiafantinel@gmail.com 